Check for updates

Cite this: Sustainable Energy Fuels, 2019, 3, 1790

\section{Evaluation of fluorine and sulfonic acid co- functionalized graphene oxide membranes under hydrogen proton exchange membrane fuel cell conditions $\uparrow$}

\author{
Robin Sandström, (D) a Alagappan Annamalai, (D) a Nicolas Boulanger, ${ }^{a}$ \\ Joakim Ekspong, ${ }^{a}$ Alexandr Talyzin, (D) a Inge Mühlbacher ${ }^{\mathrm{b}}$ and Thomas Wågberg (D) *a
}

\begin{abstract}
The use of graphene oxide (GO) based membranes consisting of self-assembled flakes with a lamellar structure represents an intriguing strategy to spatially separate reactants while facilitating proton transport in proton exchange membranes (PEMs). Here we chemically modify GO to evaluate the effect of fluorine and sulfonic acid groups on the performance of $\mathrm{H}_{2} / \mathrm{O}_{2}$ based PEM fuel cells. Mild fluorination is achieved in the presence of hydrogen fluoride during oxidation and subsequent sulfonation resulted in fluorine and $\mathrm{SO}_{3}{ }^{-}$co-functionalized GO. Membrane electrode assembly performance under low temperature and moderate humidity conditions suggested that both functional groups contribute to reduced $\mathrm{H}_{2}$ crossover compared to appropriate reference membranes. Moreover, fluorine groups promoted an enhanced hydrolytic stability while contributing to the prevention of structural degradation after constant potential experiments, whereas sulfonic acid exerted a stabilizing effect by preserving proton conductivity.
\end{abstract}

Received 28th February 2019

Accepted 8th May 2019

DOI: $10.1039 / c 9 s e 00126 c$

rsc.li/sustainable-energy

\section{Introduction}

Research and development in proton exchange membrane fuel cells (PEMFCs) is well motivated by the need for fossil-free transport solutions in order to address rapidly growing concerns about climate change. The main components in a PEMFC constitute the so-called membrane electrode assembly (MEA) which is constructed from three main components: (i) a diffusion layer with appropriately tuned wettability, (ii) an active layer made of a high surface area Pt catalyst and (iii) a proton conducting membrane. Each component is based on advanced materials with suitable properties, well-matched to coexist in a MEA operating under harsh conditions. The compatibility between each component as well as the fabrication process of the MEA is therefore crucial to the final device performance.

The most common PEMFC fuel is hydrogen, but alternatives including formic acid (direct formic acid fuel cells, DFAFCs) ${ }^{1}$ or

\footnotetext{
${ }^{a}$ Department of Physics, Umeå University, Umeå 90187, Sweden. E-mail: thomas. wagberg@umu.se

${ }^{b}$ Polymer Competence Center Leoben GmbH PCCL, Leoben 8700, Austria

$\dagger$ Electronic supplementary information (ESI) available: Additional synthesis and characterization experimental details, photographic images, thickness measurements, supporting XRD table, supporting XPS table detailing chemical species, Raman analysis, TEMs, zeta potential measurements, MEA illustration, reference polarization curve (Nafion) and cross-sectional SEM images. See DOI: 10.1039/c9se00126c
}

methanol (direct methanol fuel cells, DMFCs) ${ }^{2}$ are promising for portable applications, demonstrating a high flexibility of the proton exchange membrane (PEM) devices. In fact, PEM technology can even be used for reverse reaction, such as the production of hydrogen through electrolysis., ${ }^{3,4}$ Often, the research and development of new MEA components of a particular PEM configuration can stimulate advances in other systems utilizing the PEM concept.

Large efforts have been devoted to the field of PEMFCs, particularly to the sluggish oxygen reduction reaction (ORR) that greatly hampers the overall cell performance..$^{5-7}$ The solid membrane, acting as both an electrolyte and a separator of reactants, is however also a bottleneck with room for improvement. Requirements on the PEM are demanding, where crucial material properties include, but are not limited to, (i) chemical inertness, (ii) low permeation of reactants, (iii) proton conduction, (iv) electrical insulation, (v) stable operation in desired temperature ranges, (vi) hydrolytic stability and (vii) fabrication with low-cost environmentally sound production methods. ${ }^{8}$ So far, sulfonated polytetrafluoroethylene (Nafion ${ }^{\circledR}$ ), developed in the late 1960 's, is preferred under the majority of PEMFC operating conditions owing to a fine balance between the above-mentioned attributes. ${ }^{9,10}$ However, issues including high cost, high liquid fuel permeability rates (e.g. methanol and formic acid) and poor proton conductivity at high temperatures $\left(>80^{\circ} \mathrm{C}\right)$ and low humidity has led researchers to explore alternatives. 
Perfluorinated sulfonic acid (PFSA) materials (like Nafion) obtain their chemical and physical stability mainly from the polytetrafluoroethylene (PTFE) backbone, while the channels of sulfonic acid provide charged sites to facilitate ionic transport. Consequently, polymeric alternatives such as aromatic thermoplastic poly(ether ether ketone) (PEEK) can be modified by the attachment of sulfonic acid groups (SPEEK) to enhance the proton conductivity. ${ }^{\mathbf{1 1 , 1 2}}$ In addition, fluorination of this polymer (F-SPEEK) has been employed for enhanced gas separation. ${ }^{\mathbf{1 3 , 1 4}}$ Inan et al. ${ }^{15}$ also produced SPEEK/poly vinylidine fluoride polymeric blends and demonstrated improved chemical stability and methanol separation properties, to the cost of lowered water uptake and proton conductivity with increased fluorocarbon content. Other examples of promising polymer membranes currently under development include poly(arylene ether sulfone) derivatives $^{16-18}$ as well as multi-block polymers, ${ }^{19-21}$ where chemical modifications such as sulfonation are also considered.

As an alternative to polymer electrolytes, graphene oxide (GO) consists of two-dimensional flakes of few-layered oxidized carbon sheets and can be filtered from its colloidal dispersion into paper-like membranes with an ordered lamellar structure. ${ }^{22} \mathrm{GO}$ is synthesized from abundant natural graphite flakes and thereby considered as an attractive low-cost option for PEMs containing inter-flake channels rich of negatively charged functionalities for ionic transport. Innovative procedures employed to use such structures as PEMs include laminating a thin reactant barrier to Nafion, ${ }^{23-25}$ Nafion or SPEEK polymeric composites for interconnecting proton conducting channels ${ }^{\mathbf{2 6 - 3 0}}$ and as freestanding membranes. ${ }^{31,32}$ Recently, Bayer et al. ${ }^{33}$ used GO dispersions combined with a spray methodology to directly cover a gas diffusion electrode for MEA fabrication establishing a lamellar catalyst coated membrane structure. At a membrane thickness of $3 \mu \mathrm{m}$, a maximum power output of $\sim 80 \mathrm{~mW} \mathrm{~cm}^{-2}$ could be measured in an $\mathrm{H}_{2}$ /air PEMFC, demonstrating that assembling such membranes can be industrially favorable and not limited to filtration methods.

As for polymers, sulfonation of GO membranes is also beneficial for proton transport. ${ }^{34,35}$ Fluorinated graphene derivatives on the other hand, despite their diverse and intriguing qualities, have been scarcely implemented and tested in practical applications. In fact, to the best of our knowledge, no functionalities of this sort have ever been explored for GObased PEM applications. The main characteristics of F-modified graphene which motivate its use in PEMFCs include PTFE-like chemical inertness, electrical insulation, thermal stability and tunable wetting characteristics. ${ }^{36-40}$

Herein, fluorinated and sulfonated co-functionalized graphene oxide membranes were prepared by employing a novel method resulting in a low concentration $(\sim 0.5 \%)$ of both fluorine and $\mathrm{SO}_{3}{ }^{-}$groups which was shown to have a major influence on the wetting characteristics. Fluorination also demonstrated improved hydrolytic stability and lowered $\mathrm{H}_{2}$ crossover and had a positive role in preserving the lamellar structure under PEMFC conditions, while $\mathrm{SO}_{3}{ }^{-}$functionalization was necessary to maintain proton conductivity. Altogether we show that GO-derived twodimensional PFSA equivalent membranes represent a compelling prospect for PEM applications.

\section{Experimental methods}

\subsection{Synthesis of graphene oxide}

By far, the most frequently used methods in the literature to prepare graphene oxide are slightly different varieties of the socalled "modified Hummers' method". ${ }^{41,42}$ This process commonly involves a pre-oxidation procedure of graphite with $\mathrm{K}_{2} \mathrm{~S}_{2} \mathrm{O}_{8}$ and $\mathrm{P}_{4} \mathrm{O}_{10}$ in concentrated $\mathrm{H}_{2} \mathrm{SO}_{4}$, in order to facilitate improved graphite oxidation in the subsequent main oxidation step (see the ESI $\dagger$ for details). Such pre-oxidized graphite was used for increasing the yield of fluorinated graphene oxide, which was based on "Tours" graphene oxide, but commonly also known in the literature as the "Improved method". ${ }^{43}$

$0.5 \mathrm{~g}$ of the pre-oxidized graphite powder was placed in a Teflon beaker and dispersed in $\mathrm{H}_{2} \mathrm{SO}_{4}$ and $\mathrm{H}_{3} \mathrm{PO}_{4}(85 \%)$ at a $9: 1$ ratio. Then $10 \mathrm{~g}$ of ammonium fluoride $\left(\mathrm{NH}_{4} \mathrm{~F}\right)$ was slowly added under stirring and placed on a hotplate heated to $60{ }^{\circ} \mathrm{C}$ (solution temperature approximately $53-54{ }^{\circ} \mathrm{C}$ ). After $2 \mathrm{~h}, 2.25 \mathrm{~g}$ of potassium permanganate was added and the dispersion was then maintained for $12 \mathrm{~h}$. The mixture was slowly diluted with $0{ }^{\circ} \mathrm{C}$ ice-cold $\left(\mathrm{H}_{2} \mathrm{O}\right)_{\text {DI }}$ (water) while surrounded by an ice-bath, followed by addition of $1.5 \mathrm{ml} \mathrm{H}_{2} \mathrm{O}_{2}(30 \%)$. The white/yellow dispersion was then separated into falcon tubes and washed repeatedly $\left(4 \times\right.$ each) with $10 \% \mathrm{HCl},\left(\mathrm{H}_{2} \mathrm{O}\right)_{\mathrm{DI}}$ and finally ethanol (99.5\%). The resulting alco-gel was spread out on a Petri-dish and left to dry overnight in a well-ventilated ambient atmosphere. In addition to the fluorinated GO (denoted as F-TGO), it was deemed necessary to prepare reference samples based on the same method where $\mathrm{NH}_{4} \mathrm{~F}$ was omitted (TGO*) and another one where the pre-oxidation step was also omitted (TGO). Moreover, another reference based on the modified Hummers' method (HGO) was prepared, described in detail in the ESI. $\dagger$ Dispersions were produced by re-dispersion of the obtained powder into $\left(\mathrm{H}_{2} \mathrm{O}\right)_{\mathrm{DI}}\left(0.5 \mathrm{mg} \mathrm{m} \mathrm{m}^{-1}\right)$ by $1 \mathrm{~h}$ sonication and centrifugation (6000 rpm) for $1 \mathrm{~h}$ to remove small amounts of larger un-exfoliated pieces. These dispersions were then vacuum filtered (Whatman ${ }^{\circledR}$, alumina, $47 \mathrm{~mm}, 0.2 \mu \mathrm{m}$ pore size) until a dry membrane could be peeled off from the filter. All membranes were stored in a desiccator (ambient temperature) and allowed to dry for at least two weeks before they were used for characterization. Schematic illustration of the entire SF-TGO fabrication can be found in Fig. 1.

F-TGO was, for reasons discussed in the Results section, selected for sulfonation with the aryl diazonium salt of sulfanilic acid. ${ }^{44}$ First, $200 \mathrm{mg}$ of sulfanilic acid was dissolved in a basic solution containing $58 \mathrm{mg}$ sodium carbonate $\left(\mathrm{Na}_{2} \mathrm{CO}_{3}\right)$ in $2.5 \mathrm{ml}\left(\mathrm{H}_{2} \mathrm{O}\right)_{\mathrm{DI}}$ by brief heating on a $100{ }^{\circ} \mathrm{C}$ hotplate until completely dissolved. Once the mixture reached room temperature, $75 \mathrm{mg}$ sodium nitrite $\left(\mathrm{NaNO}_{2}\right)$ was added. The prepared solution was then added dropwise into an acid solution containing $1.6 \mathrm{ml} \mathrm{H}_{2} \mathrm{O}$ and $0.25 \mathrm{ml} \mathrm{HCl}(35 \%)$ in an ice-bath under vigorous stirring. The mixture was kept under stirring for 15 min to ensure complete reaction, after which a finely divided white precipitate was observed. Sulfonation was then achieved by dropwise addition of the prepared precursor into the partially reduced GO dispersion under stirring in an ice bath. 


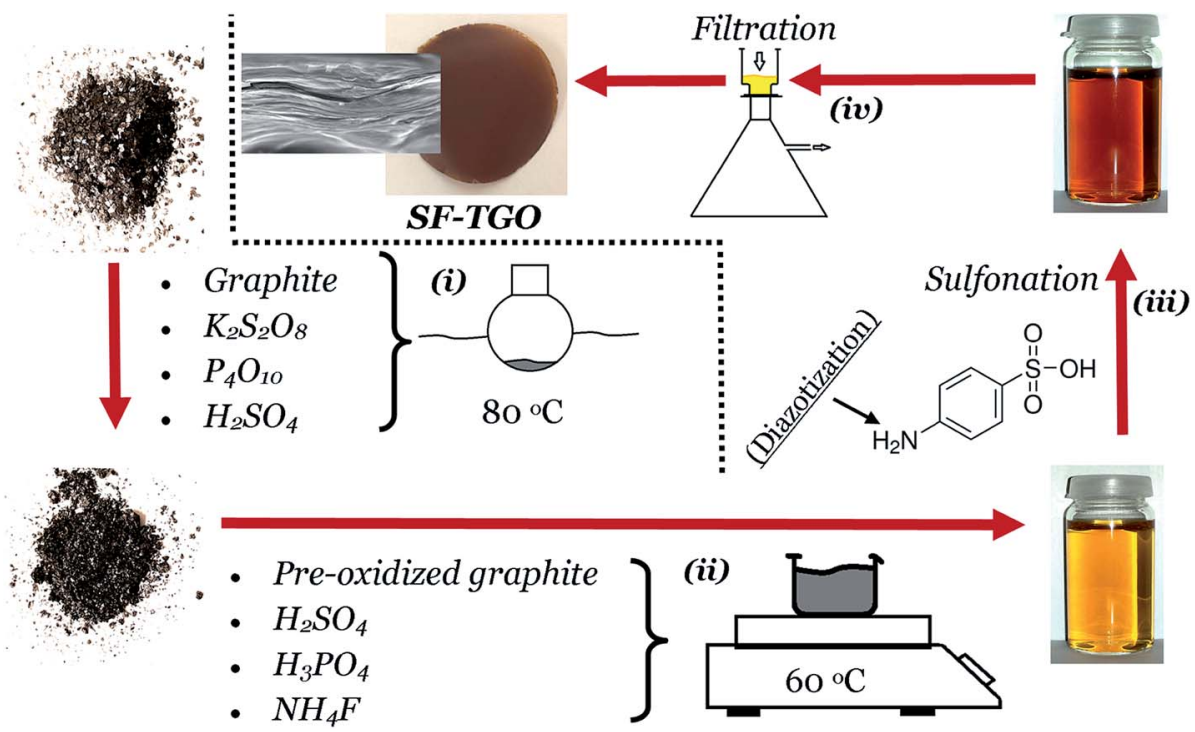

Fig. 1 Schematic illustration of the full synthesis procedure of SF-TGO membranes. The main steps involve (i) pre-oxidation of natural flake graphite, (ii) oxidation by the Tours method with added $\mathrm{NH}_{4} \mathrm{~F}$, (iii) sulfonation with the aryl diazonium salt of sulfanilic acid and finally (iv) vacuum filtration into a solid membrane. Washing procedures are not shown in this illustration.

After a reaction time of $4 \mathrm{~h}$, the remaining salts were removed by dialysis (3.5 kDa MWCO) for one week. The dispersion was used directly to fabricate membranes with the filtration procedure described above, henceforth denoted as SF-TGO.

\subsection{Physical characterization}

Thermogravimetric data were collected by using a METTLER Toledo TGA/DSC 1 setup under an $\mathrm{N}_{2}$ flow of $40 \mathrm{ml} \mathrm{min}{ }^{-1}$ at a heating rate of $10 \mathrm{~K} \mathrm{~min}^{-1}$ from $30{ }^{\circ} \mathrm{C}$ to $900{ }^{\circ} \mathrm{C}$. X-ray diffraction (XRD) was performed on membranes in both dry and wet states $\left(\mathrm{H}_{2} \mathrm{O}\right.$ soaked), covered and immobilized with plastic foil, with a Panalytical $\mathrm{X}^{\prime}$ Pert $^{3}$ Powder diffractometer with a $\mathrm{CuK}_{\alpha}(\lambda=1.5406 \AA)$ source. XRD patterns were all intensity normalized. X-ray photoelectron spectroscopy (XPS) was performed by using a Kratos Axis Ultra DLD electron spectrometer using a $150 \mathrm{~W}$ monochromatic $\mathrm{AlK}_{\alpha}$ source. Attenuated total reflectance Fourier transform infrared (ATR-FTIR) spectra were recorded by using a Vertex 80 (Bruker), where membranes were firmly pressed against a germanium (Ge) ATR crystal. All FTIR spectra were normalized with respect to the peak centered around $\sim 1600 \mathrm{~cm}^{-1}$ likely corresponding to a combination of un-oxidized $\mathrm{sp}^{2}$ domains and adsorbed water. ${ }^{45,46}$ Contact angle measurements were carried out in order to estimate the hydrophobicity of the GO membranes. Small individual droplets were placed on the dry membranes and measured with an optical tensiometer from Biolin Scientific. The angles were fitted by the Young Laplace method using Attension software.

\subsection{Membrane electrode assembly fabrication and characterization}

Hydrogen crossover measurements were performed in realistic low temperature fuel cell environments at moderate relative humidity $(75 \% \mathrm{RH})$. The as-produced membranes were carefully assembled (free-standing) together with gas diffusion electrodes (GDEs) acquired from Fuel Cell Store Inc. (0.2 mg $\mathrm{cm}^{2}, 20 \%$ Pt on Vulcan, carbon cloth). The anodes and cathodes were fed with $\mathrm{H}_{2}\left(100 \mathrm{ml} \mathrm{min}{ }^{-1}\right)$ and $\mathrm{N}_{2}\left(1000 \mathrm{ml} \mathrm{min}{ }^{-1}\right)$ respectively and the potential was swept from $0.05 \mathrm{~V}$ to $0.5 \mathrm{~V} v s$. $\mathrm{RE} / \mathrm{CE}$ (anodic ref.) with a scan rate of $50 \mathrm{mV} \mathrm{s}^{-1}$ using an 885 fuel cell potentiostat connected to an $850 \mathrm{e}$ fuel cell test station (Scribner). The measurements were performed at various temperatures ranging from $30{ }^{\circ} \mathrm{C}$ up to $70{ }^{\circ} \mathrm{C}$ with $10{ }^{\circ} \mathrm{C}$ intervals. Each LSV was recorded at least once ensuring representable curves with stable crossover-current. Stable LSVs could be achieved on all samples apart from TGO* (all temperatures) and $\mathrm{HGO}$ at $70{ }^{\circ} \mathrm{C}$.

Fuel cell polarization curves in an $\mathrm{H}_{2} / \mathrm{O}_{2}$ configuration were acquired in a non-freestanding state by assembling the MEA with a Nafion 211 membrane (N211) with an MEA area of $5 \mathrm{~cm}^{2}$ (see the ESI for the membrane pretreatment protocol and Fig. S7 $\uparrow$ for a more detailed illustration of the MEA). The membranes were sandwiched facing the anode GDE followed by N211 and finally the cathode GDE was sealed with a combination of Teflonized fiberglass and silicone rubber gaskets in a quickCONNECT cell fixture (Baltic FuelCells corp.) and connected to an 850e fuel cell test station (Scribner). All measurements were performed at $40{ }^{\circ} \mathrm{C}$ and $75 \% \mathrm{RH}$ with an $\mathrm{H}_{2}$ and $\mathrm{O}_{2}$ flow of $100 \mathrm{ml} \mathrm{min}^{-1}$ at the anode and cathode respectively. Moderate humidity was chosen as a compromise to not cause the GO membranes to become too fragile ${ }^{22,47,48}$ and at the same time providing sufficient $\mathrm{H}_{2} \mathrm{O}$ supply to promote proton conductivity particularly in the Nafion components (catalyst layer and membrane) in the MEA. Owing to the diverse properties of the membranes, multiple polarization curves were recorded at different time periods of FC operation in order to get representative data of membrane behavior. First, a curve was recorded as soon as the open circuit potential (OCP) was 
stabilized (i) followed by another after mild conditioning for $1 \mathrm{~h}$ at $0.6 \mathrm{~V}$ (ii), a third curve after an additional $8 \mathrm{~h}$ at $0.5 \mathrm{~V}$ (iii) and lastly a final one after another $8 \mathrm{~h}$ at $0.5 \mathrm{~V}$ (iv). All curves were recorded with $25 \mathrm{~mA}$ intervals until reaching $0.3 \mathrm{~V}$ with a stabilization time of $30 \mathrm{~s}$ per data point.

\section{Results}

Fig. $\mathrm{S} 1 \uparrow$ depicts dispersions produced directly after the synthesis of fluorinated (F-TGO) and sulfonated/fluorinated (SF-TGO) GO as well as the three reference membranes (TGO, TGO* and HGO). A notably different visual appearance is seen for F-TGO in comparison to the reference samples. The F-TGO membranes produced via filtration were immediately noted to be significantly more stable in neutral $\mathrm{H}_{2} \mathrm{O}$ than all the other reference materials (see Fig. S2 $\dagger$ ), and could even preserve this property after being sulfonated. The property of high structural stability under high humidity conditions is desired for all MEA components within the PEMFC. The thicknesses of all membranes as measured by a micrometer tool ranged from 7 to $9 \mu \mathrm{m}$ (Table S1 $\dagger$ ), while it was also noted that here the handling of F-TGO and SF-TGO without breakage was notably easier, suggesting enhanced mechanical robustness. This is also supported by a significantly enhanced flexibility as a result of fluorination, as shown in bend radius measurements illustrated in Fig. S3. $\dagger$

Thermogravimetric curves recorded under a $\mathrm{N}_{2}$ atmosphere of respective synthesized GO powder and the resulting membranes are shown in Fig. 2a and b respectively. The TGA profile of GO can be divided into three parts: desorption of surface water at $T<\sim 200^{\circ} \mathrm{C}$, explosive exfoliation and release of steam and $\mathrm{CO}_{2}$ around $200^{\circ} \mathrm{C}$ and continued reduction of more firmly attached functional groups defined by a more shallow slope $^{43}$ at $T>\sim 200{ }^{\circ} \mathrm{C}$. Here, all as-synthesized GO powders followed such a characteristic trend for graphene oxide while FTGO has a slightly higher exfoliation temperature by about 30 ${ }^{\circ} \mathrm{C}$, indicating that the addition of $\mathrm{NH}_{4} \mathrm{~F}$ might have altered the inter-flake attractions. The same TGA experiments performed after vacuum filtration into membranes show similar trends (Fig. 2b), albeit with slightly upshifted exfoliation temperatures $\left(\sim 10-20{ }^{\circ} \mathrm{C}\right)$, likely related to the strength of the interlayer interactions formed during self-assembly. X-ray diffraction was performed under both dry and wet conditions on the prepared membranes as shown in Fig. 1c. In the dry phase, F-TGO had a slight increase in the interlayer distance signified by the $\mathrm{C}(002)$ reflection $\left(2 \theta=10.3^{\circ}\right)$ compared to that of $\mathrm{HGO}$ and TGO $\left(2 \theta=10.9^{\circ}\right)$, which can be attributed to a more repulsive effect of the $\mathrm{F}$ functionalities. ${ }^{49}$ Sulfonation shifted the $\mathrm{C}(002)$ peaks to higher angles $\left(10.8{ }^{\circ} \mathrm{C}\right)$ indicating attractive interactions between the layers as a result of sulfonic acid. ${ }^{32}$ Although the interlayer spacing under dry conditions differs slightly (see Table S2 $\uparrow$ ), the similar swelling behavior suggests that the maximum water uptake is nearly identical for all membranes (with the exception of TGO*), which is already documented for modified Hummers' GO. ${ }^{50}$ It is noteworthy however to recall that the stability of F-TGO and SF-TGO in the wet state is superior to that of $\mathrm{HGO}$ and TGO (Fig. S2 $\dagger$ ), despite the similar interlayer distances.
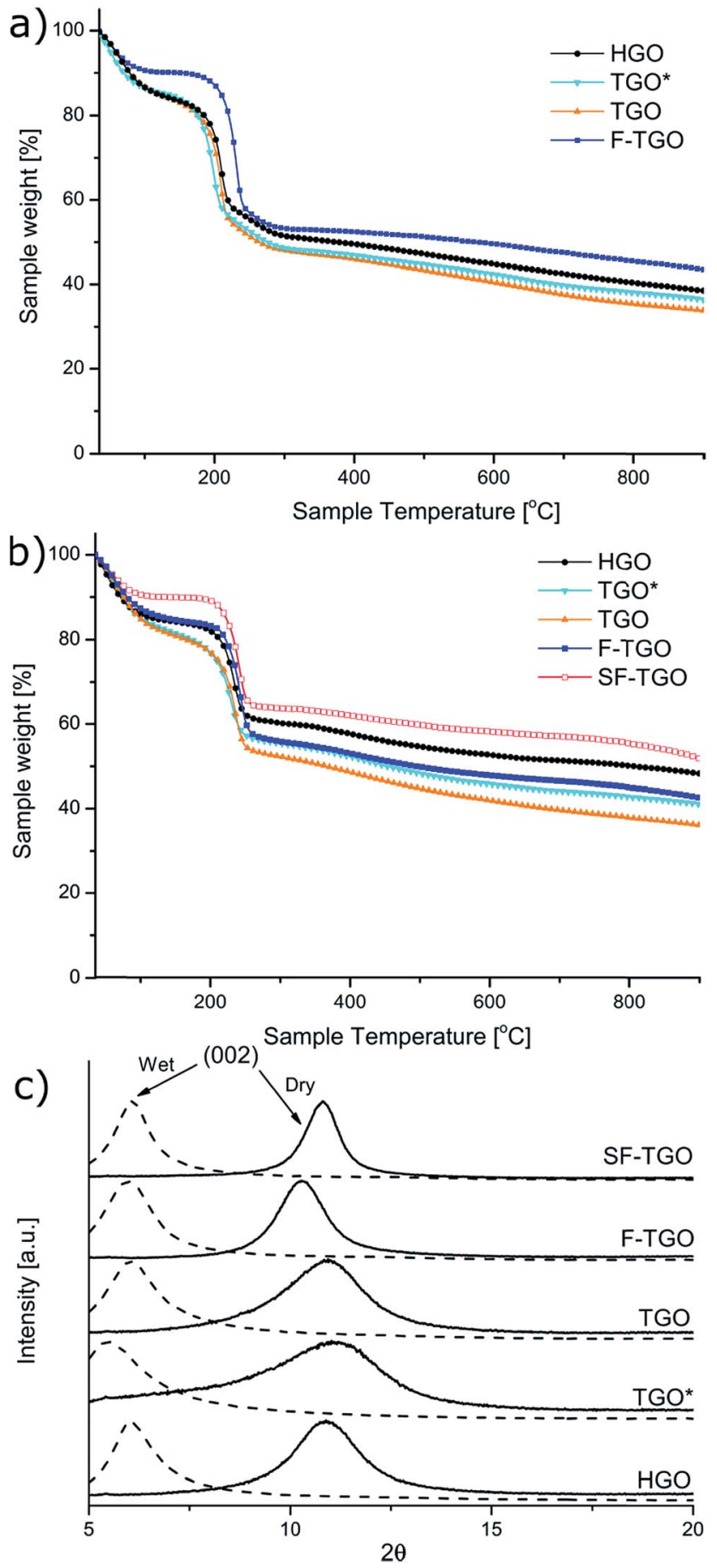

Fig. 2 Thermogravimetric measurements of the synthesized graphite oxides (a) and membranes (b) respectively in an $\mathrm{N}_{2}$ gas-flow from 30 ${ }^{\circ} \mathrm{C}$ to $900{ }^{\circ} \mathrm{C}$. X-ray diffraction patterns (c) of the membranes in dry (solid line) and wet (dashed line) states.

Comparable synthesis procedures have previously been suggested to produce $\mathrm{F}$ functional groups of a semi-ionic nature attached to GO flakes..$^{39,49,51}$ In our case the binding energy of the F 1s band of $686.5 \mathrm{eV}$, as measured by X-ray photoelectron spectroscopy (Fig. 3a, b and Table S3†), may also suggest that such functionalities are present, where the atomic 

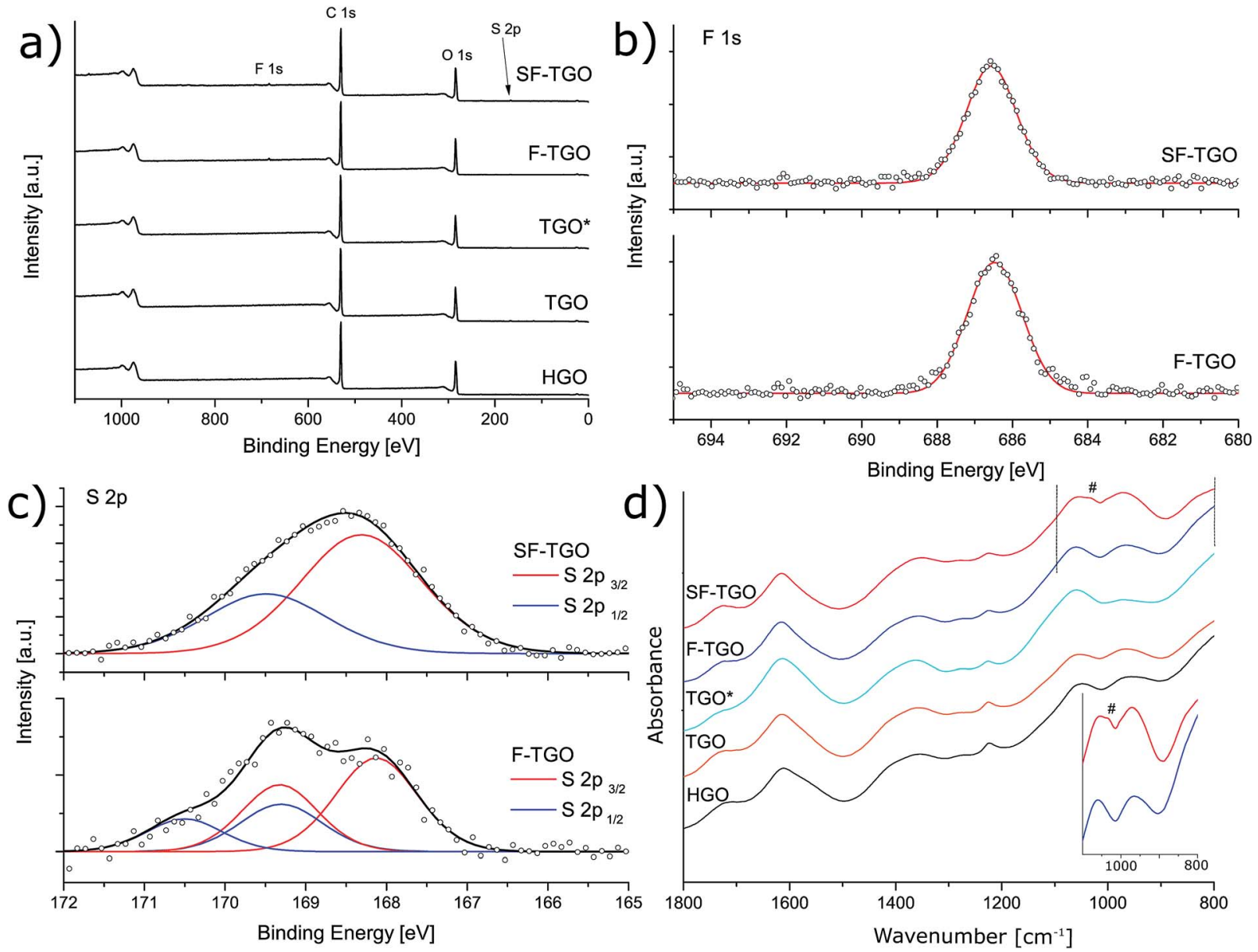

Fig. 3 X-ray photoelectron spectroscopy measurements including survey spectra (a), F 1s (b) and S $2 p$ (c) core-level regions respectively. Attenuated total reflectance Fourier transform infrared spectroscopy data (d) of membranes where the inset shows the $\mathrm{C}-\mathrm{H}$ vibrational region corresponding to the disubstituted phenyl compound of the aryl sulfonic acid group.

concentration of $\mathrm{F}$ is measured to be $\sim 0.5 \%$. However, the presence of HF-type species cannot be entirely excluded owing to their similar binding energies to semi-ionic F. ${ }^{52}$ No significant changes in oxygen groups were detected (see the $\mathrm{C} 1 \mathrm{~s}$ band in Table S3 $\dagger$ ) and the degree of oxidation was similar with a $\mathrm{C} / \mathrm{O}$ ratio of 2.0-2.2, for all samples except for TGO* showing a C/O value as low as 1.7 , indicating a severe over-oxidation of the latter sample also supported by TEM images showing damaged perforated flakes (Fig. S4†). As a result, TGO* based membranes were very fragile in comparison to other samples (although no

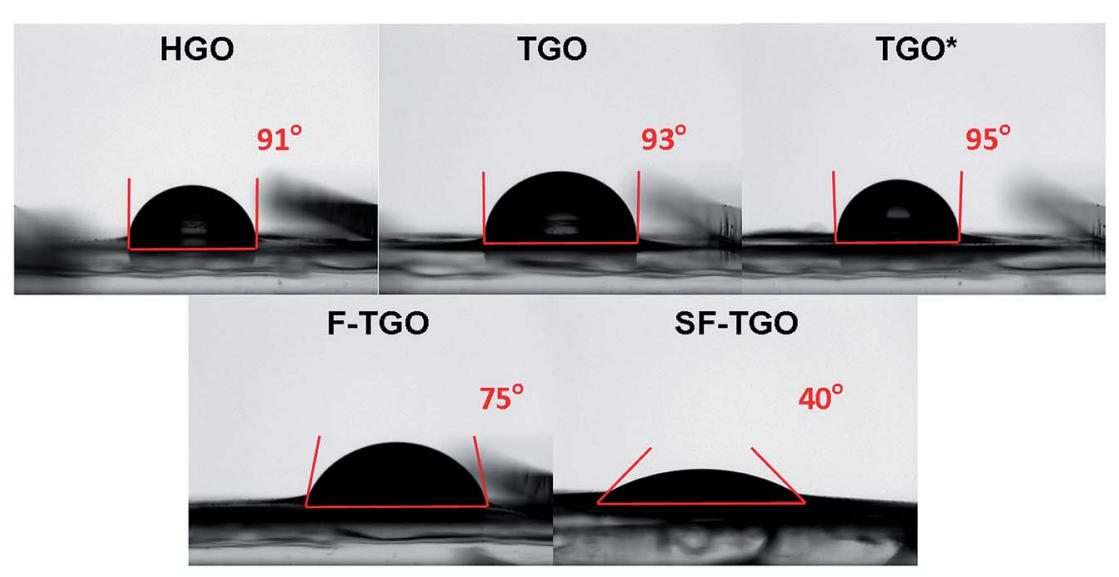

Fig. 4 Contact angle measurements for wettability determination. Reference membranes (top row) all show higher hydrophobicity than the membranes prepared from chemically modified GO (bottom). 
change in the $\mathrm{D} / \mathrm{G}$ ratio could be detected by Raman spectroscopy, Fig. S5 $\dagger$ ). The reason for avoiding over-oxidation in F-TGO can likely be attributed to the formation of ammonium hydrogen sulfate $\left(\left(\mathrm{NH}_{4}\right) \mathrm{HSO}_{4}\right)$ in the $\mathrm{H}_{2} \mathrm{SO}_{4}$-rich mixture by the reaction

$$
\mathrm{NH}_{4} \mathrm{~F}+\mathrm{H}_{4} \mathrm{SO}_{4} \rightarrow\left(\mathrm{NH}_{4}\right) \mathrm{HSO}_{4}+\mathrm{HF},
$$

which is a weaker acid than $\mathrm{H}_{2} \mathrm{SO}_{4}$. The combination of preoxidation and $\mathrm{NH}_{4} \mathrm{~F}$ addition thus tuned the overall oxidation strength such that F-TGO (and consequently SF-TGO) attained a similar C/O ratio to the TGO and HGO reference samples. Mild fluorination with HF radicals present under oxidative conditions has also previously been observed, attributed to substitution reactions. ${ }^{51,53}$ The use of aqueous HF such as in ref. 51 also yields similar results. However, $\mathrm{NH}_{4} \mathrm{~F}$ was preferred in our case due to the significantly lower release of hazardous gases during the reaction.

F-TGO preserved the vast majority of $\mathrm{F}$ species throughout the whole sulfonation procedure, including thorough washing by dialysis, indicating a firm attachment of the F functionalities. Successful sulfonation is supported by a clear increase in the signal at $168.2 \mathrm{eV}$ representing the $\mathrm{S} 2 \mathrm{p}_{3 / 2}$ core-level region, ${ }^{54}$ from $0.1-0.2 \%$ for the reference samples to nearly $0.6 \%$ after sulfonation (see Fig. 3c), thus providing a good estimate of the degree of sulfonation which is $\sim 0.5 \%$. The addition of $\mathrm{SO}_{3}{ }^{-}$ groups in the bulk membrane is further manifested by an increase in ion-exchange capacity (IEC) from $\sim 1.2 \mathrm{mmol} \mathrm{g}^{-1}$ (FTGO) to $\sim 1.5 \mathrm{mmol} \mathrm{g}^{-1}$ (SF-TGO), as measured by the procedure shown in the ESI (eqn (S1) $\dagger$ ). Sulfonation is also supported by ATR-FTIR (Fig. 3d) showing emerging characteristic vibrations of the disubstituted phenyl group at $\sim 1030 \mathrm{~cm}^{-1}$ corresponding to $\mathrm{C}-\mathrm{H}$ in-plane bending accompanied by a shoulder near 840 $\mathrm{cm}^{-1}$ attributed to the out-of-plane wagging. ${ }^{\mathbf{4 4 , 5 5}}$ Moreover, the FTIR spectra show signs of $\mathrm{C}=\mathrm{O}\left(\sim 1720 \mathrm{~cm}^{-1}\right), \mathrm{C}-\mathrm{OH}(\sim 1060$ $\left.\mathrm{cm}^{-1} \& \sim 1360 \mathrm{~cm}^{-1}\right)$, epoxy or peroxide $\left(\sim 970 \mathrm{~cm}^{-1}\right)$ and epoxy $\mathrm{C}-\mathrm{O}-\mathrm{C}\left(\sim 1230 \mathrm{~cm}^{-1}\right)$ without excluding the possibility of overlapped sulfate vibrations on the latter. ${ }^{\mathbf{4 5 , 4 6 , 5 6 , 5 7}}$ The similarities in O-functional groups between the samples are thus clearly seen in the spectra, supporting the above C 1s XPS data (Table S3 $\dagger$ ). However, no clear signs of $F$ species could be detected above the noise level by ATR-FTIR.

Contact angle measurements performed on the GO membranes are shown in Fig. 4. While all membranes prepared from conventional oxidation procedures showed contact angles of $91-95^{\circ}$, the F-TGO membrane was clearly more hydrophilic $\left(75^{\circ}\right)$ which is in line with previously reported studies of fluorinated graphene oxide. ${ }^{38,58}$ This phenomenon can be attributed to a lowered free surface energy at the membrane $\mid \mathrm{H}_{2} \mathrm{O}$ interface due to hydrogen bonding interactions between the $\mathrm{H}$ (in water) and the highly electronegative $\mathrm{F}$ atoms. Moreover, the addition of hydrophilic $\mathrm{SO}_{3}{ }^{-}$groups further lowered the contact angle to $40^{\circ}$. Zeta potential measurements were measured on the dispersions produced prior to the filtration step (Fig. S6†). Although measurement points with slightly lowered potentials in the $\mathrm{pH}$ region between 4 and 7 were detected for F-TGO and SF-TGO, hinting at greater flake-to-flake electrostatic repulsion, no firm conclusions can be drawn from the Zeta potential measurements owing to relatively high standard deviations.
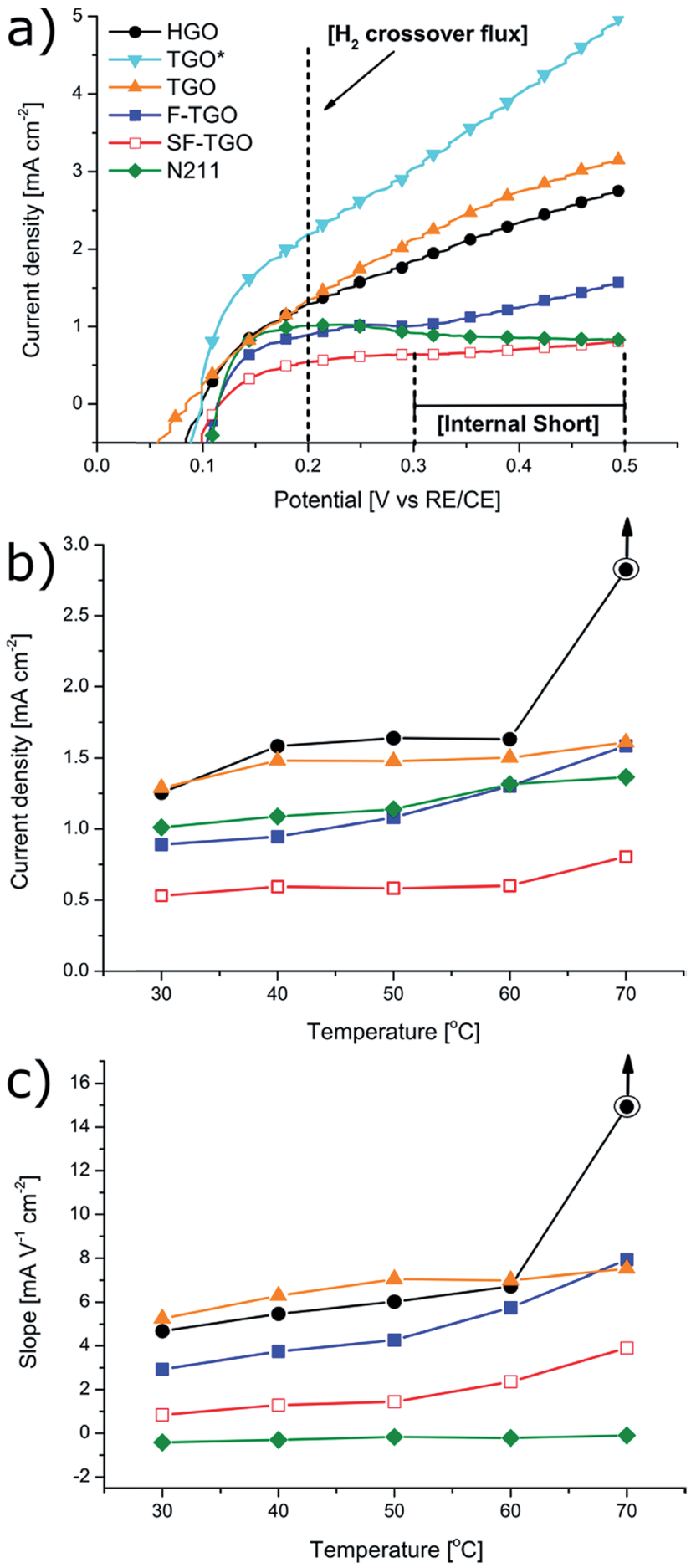

Fig. 5 In situ $\mathrm{H}_{2}$ crossover measurements of freestanding membranes performed with commercial electrodes and an $\mathrm{N}_{2}$ saturated cathode at $75 \% \mathrm{RH}$ and $30{ }^{\circ} \mathrm{C}$ (a). The measured crossover current at $0.2 \mathrm{~V}$ (b) and the slope in the $0.3-0.5 \mathrm{~V}$ region (c) illustrating the through-plane internal short (lower is better). Stable LSVs could not be recorded for $\mathrm{HGO}$ at $70{ }^{\circ} \mathrm{C}$ as well as TGO* at all temperatures indicated by the arrow in (b) and (c). Note: GO membranes ranged in thicknesses from 7-9 $\mu \mathrm{m}$ in contrast to N211 (25 $\mu \mathrm{m})$. 
The permeation of $\mathrm{H}_{2}$ through the proton exchange membrane (crossover) can be estimated directly in a single PEMFC by first feeding the cathode with an inert gas such as $\mathrm{N}_{2}$. Since the $\mathrm{H}_{2}$ flow remains at the anode, the potential can be linearly swept into a potential window where any molecular $\mathrm{H}_{2}$ present at the cathode is immediately oxidized. ${ }^{59,60}$ Fig. 5a shows such a procedure performed on the free-standing as-synthesized GO membranes at $30{ }^{\circ} \mathrm{C}$ and $75 \% \mathrm{RH}$ as well as a Nafion type 211 (N211) membrane for comparison purposes. Typically, a plateau is formed above $\sim 0.2 \mathrm{~V}$ corresponding to the rate of $\mathrm{H}_{2}$ permeation. However, whenever there is a linear increment of current with voltage, there is a sign of internal shorting, where the slope is directly related to the severity of the through-plane electrical short of the membrane. Taking this into consideration, both the crossover current near the hydrogen evolution onset at $0.2 \mathrm{~V}$ and the slopes formed between 0.3 and $0.5 \mathrm{~V}$ are presented in Fig. $5 \mathrm{~b}$ and $\mathrm{c}$ respectively, for temperatures up to $70{ }^{\circ} \mathrm{C}$, in order to represent in situ temperature dependent trends in membrane characteristics. TGO* was however significantly more fragile than the others and stable LSVs could not be recorded, presumably due to increased breakage in the compressed MEA. A similar effect was also observed for $\mathrm{HGO}$ at $70{ }^{\circ} \mathrm{C}$, consistent with previously observed instability likely owing to partial reduction of Hummers' GO under PEMFC conditions with an onset near 70 ${ }^{\circ} \mathrm{C}^{61}$ Interestingly, TGO did not have this problem, suggesting that the synthesis of GO through the Tours method is to be preferred if such conditions are required. Roughly, the $\mathrm{H}_{2}$ permeation rate below $50{ }^{\circ} \mathrm{C}$ followed a trend of $\mathrm{TGO}^{*}>\mathrm{TGO} \approx$ $\mathrm{HGO}>\mathrm{F}-\mathrm{TGO} \approx \mathrm{N} 211>\mathrm{SF}-\mathrm{TGO}$, while it is important to note that the commercial Nafion membrane (N211) has more than double the thickness $(25 \mu \mathrm{m})$. These results are in line with the superior
$\mathrm{H}_{2}$ blocking performance of GO membranes as observed previously, ${ }^{33}$ although they are most often measured under lowhumidity conditions. Due to the severe internal short of some of the membranes as well as a fairly non-linear trend, especially at higher temperatures (possibly due to side-reactions), internal short correction for calculation of precise in situ permeability rates could not be performed. Considering that electrical short within the PEM is a contributing factor to poor performance and low OCP, ${ }^{62}$ reaching sufficient electrical insulation thus poses an additional challenge in developing GO membranes.

The performance in an $\mathrm{H}_{2} / \mathrm{O}_{2}$ configuration was evaluated and polarization curves after various operational time periods are shown in Fig. 6. Testing GO-based membranes under real fuel cell conditions has proven to be a challenge and typically the membranes can either be stabilized with a commercial one, laminated or used directly as a freestanding PEM but limited to a small cell area if the membrane is deemed durable enough. Here, the GO membranes, covering the whole $5 \mathrm{~cm}^{2}$ cell, are backed with a N211 facing the cathode protecting the direct contact of $\mathrm{H}_{2}$ with $\mathrm{O}_{2}$ in the case of pinhole formation, as illustrated in detail in Fig. S7. $\dagger$ In fact, brief experiments where freestanding membranes were used showed a sharp drop in the OCP down to $\sim 0 \mathrm{~V}$ at random points during operation, indicating a failure of barricading the $\mathrm{H}_{2}$ from the cathode in short to medium term operation under these conditions. This N211backed MEA configuration was thus necessary in order to get a meaningful view of the temporal evolution of fuel cell performance, where the relative ohmic drops signify the differences in through-plane proton conductivity. As expected, the total proton conductivity due to the added GO membrane clearly decreased, as can be clearly seen by comparing the stable
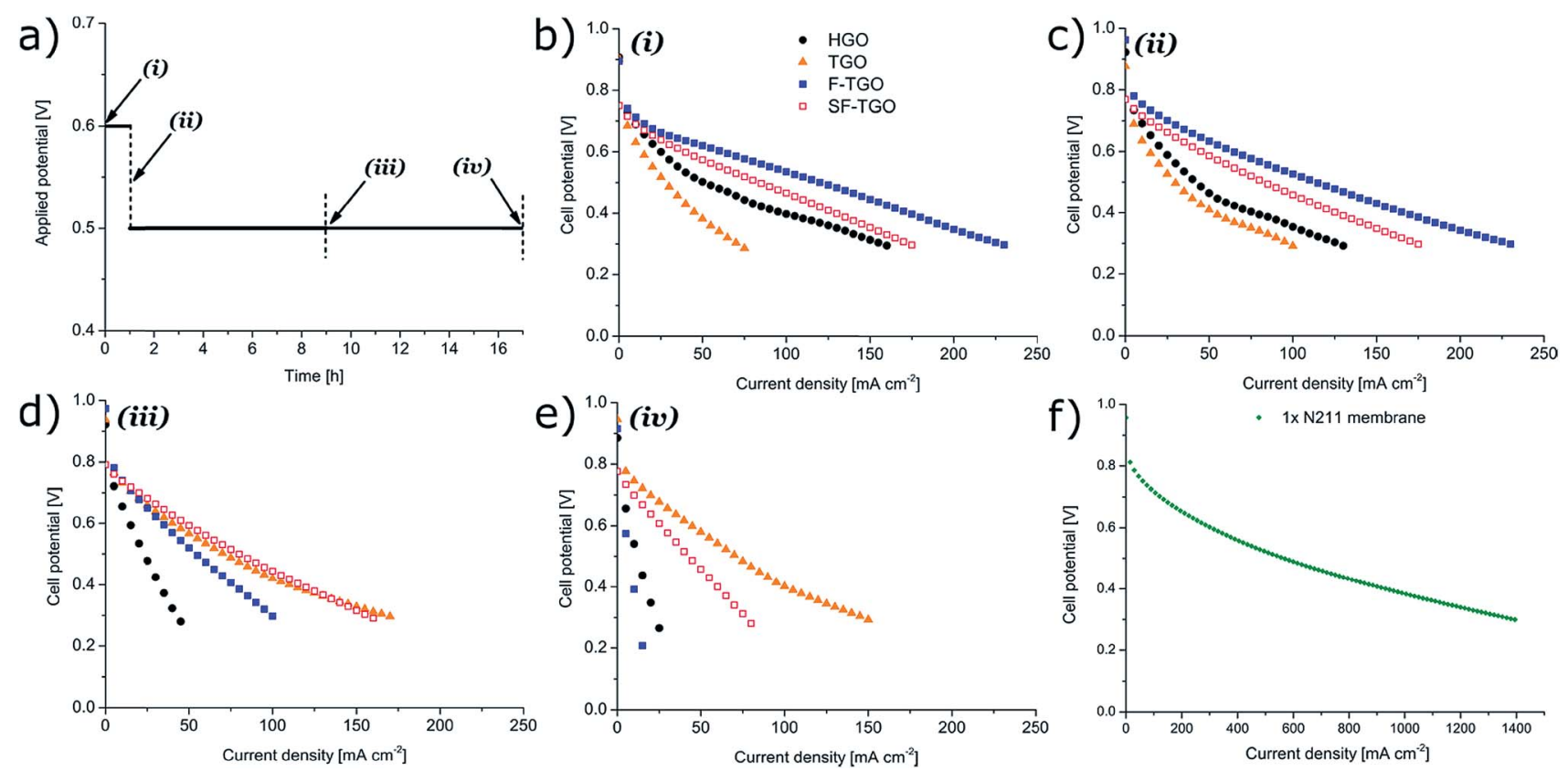

Fig. 6 Polarization curves of an anode|GO|N211|cathode MEA system at $40{ }^{\circ} \mathrm{C}$ and $75 \% \mathrm{RH}$ recorded after operation according to the illustration in (a). The curves were recorded initially after stable OCP was achieved (i) (b), after mild operation at $0.6 \mathrm{~V}$ (ii) (c) and after two separate runs at 0.5 $\checkmark$ (iii $\&$ iv) ( $\&$ e). Stable performance of the single Nafion 211 membrane is shown in (f). 
MEA performance of a single N211 membrane (Fig. 6f). Note however that $\mathrm{TGO}^{*}$ was excluded from these measurements due to the extreme brittleness that caused it to break immediately when contacting the heavily humidified N211 membrane.

As shown in the polarization profiles in Fig. 6b-e with corresponding current vs. time curves presented in Fig. S8, $\dagger$ all membranes had diverse performances. Overall, the performance evolved from initially $\mathrm{TGO}<\mathrm{HGO} \approx \mathrm{SF}-\mathrm{TGO}<$ F-TGO into F-TGO $\approx \mathrm{HGO}<\mathrm{SF}-\mathrm{TGO}<\mathrm{TGO}$ after $1 \mathrm{~h}$ at $0.6 \mathrm{~V}$ plus an additional $16 \mathrm{~h}$ at $0.5 \mathrm{~V}$. First, we note that sulfonation of F-TGO had a stabilizing effect as shown by the superior stability of SF-TGO, whereas FTGO degraded at a similar rate to that of HGO. In contrast, the only membrane that showed an increase in performance with time was TGO. Coincidentally, as shown by the cross-sectional SEM micrographs in Fig. S10 and S11, $\dagger$ the only membrane with notable severe structural disruption to the laminar framework after FC operation was also TGO. These observations suggest that structural degradation of the GO membrane, reducing the protonic travel path, can enhance the performance in this MEA configuration, thus highlighting that caution must be exercised when interpreting results from membranes tested with similar cell designs. Nevertheless, the results advocate that the addition of fluorine groups prevented such structural degradation implying that the performance loss of F-TGO should be assigned to a degradation of a chemical nature. In addition, the open circuit potential can normally be used as an indicator of fuel crossover since usually $\mathrm{H}_{2}$ permeation is the main contributing factor to low OCP. ${ }^{63}$ However, as shown in ESI Fig. S9, $\uparrow$ the majority of OCP values that were recorded prior to measuring polarization curves were lower than that measured from a single N211 membrane. This observation in combination with the lack of correlation to the measurements in Fig. 5 (at $40{ }^{\circ} \mathrm{C}$ and $75 \%$ $\mathrm{RH}$ ) implies that the main cause of lowered OCP lies elsewhere. Overall, it can be argued that the preservation of structural integrity combined with a relatively slow decline in performance implies that SF-TGO would most likely be the best performer in hypothetical freestanding equivalent experiments.

\section{Conclusions}

In summary, we fabricated membranes entirely based on graphene oxide through a vacuum filtration method. Mild fluorination was successfully achieved by introducing $\mathrm{HF}$ species during the oxidation procedure, based on the Tours method, with $\mathrm{NH}_{4} \mathrm{~F}$ as an F-precursor. Subsequent sulfonation resulted in a membrane with $\mathrm{F}$ and $\mathrm{SO}_{3}{ }^{-}$co-functionalized flakes as evidenced by XPS, ATR-FTIR and contact angle measurements. The F-groups prevented membrane re-dispersion in neutral $\mathrm{H}_{2} \mathrm{O}$, thus demonstrating promising structural stability under high-humidity conditions (hydrolytic stability) despite showing similar water uptake to reference membranes.

The role of fluorine and sulfonic acid groups attached to the GO flakes was evaluated in realistic fuel cell environments by comparing them with appropriate reference materials. At low temperatures and moderate humidity, diverse properties were detected in $\mathrm{H}_{2}$ crossover in situ measurements where both $\mathrm{F}$ and $\mathrm{SO}_{3}{ }^{-}$had a beneficial influence. Moreover, multiple polarization curves under low temperature $\mathrm{H}_{2} / \mathrm{O}_{2}$ conditions were recorded and evaluation of the results suggests that the Fgroups prevented structural degradation that was observed in the membrane prepared from the conventional Tours method. Despite demonstrating relatively high initial performance, there was a rapid loss in the performance of the F-based membrane that was in addition shown to be alleviated by sulfonation. Further optimization work including achieving an appropriate concentration and balance of $\mathrm{F}$ and $\mathrm{SO}_{3}{ }^{-}$as well as selecting appropriate oxidation methods remains to be performed.

\section{Conflicts of interest}

There are no conflicts of interest to declare.

\section{Acknowledgements}

T. W. acknowledges support from Vetenskapsrådet (201704862) Energimyndigheten (45419-1), Interreg Nord, Region Västerbotten, and Ångpanneföreningen (15-483). The authors acknowledge the Umeå Core Facility for Electron Microscopy (UCEM) at Umeå University, Chemical Biological Centre (KBC). Andrey Shchukarev at Umeå University, KBC, is further acknowledged for performing the XPS measurements. I. M. acknowledges the K-Project "PolyTherm" at the Polymer Competence Center Leoben GmbH (PCCL, Austria) within the framework of the COMET-program of the Federal Ministry for Transport, Innovation and Technology and Federal Ministry for Science, Research and Economy with contributions by the Graz University of Technology (Institute for Chemistry and Technology of Materials as well as the HRSM-Soft Matter Application Lab), the Montanuniversitaet Leoben, and the Delft University of Technology. Funding was provided by the Austrian Government and the State Government of Styria.

\section{References}

1 X. W. Yu and P. G. Pickup, J. Power Sources, 2008, 182, 124-132. 2 V. Neburchilov, J. Martin, H. J. Wang and J. J. Zhang, J. Power Sources, 2007, 169, 221-238.

3 D. Bessarabov, H. Wang, H. Li and N. Zhao, PEM Electrolysis for Hydrogen Production: Principles and Applications, CRC Press, 2016.

4 M. Carmo, D. L. Fritz, J. Merge and D. Stolten, Int. J. Hydrogen Energy, 2013, 38, 4901-4934.

5 H. A. Gasteiger, S. S. Kocha, B. Sompalli and F. T. Wagner, Appl. Catal., B, 2005, 56, 9-35.

6 V. Mehta and J. S. Cooper, J. Power Sources, 2003, 114, 32-53. 7 J. Zhang, PEM Fuel Cell Electrocatalysts and Catalyst Layers: Fundamentals and Applications, Springer London, 2008.

8 Y. Wang, K. S. Chen, J. Mishler, S. C. Cho and X. C. Adroher, Appl. Energy, 2011, 88, 981-1007.

9 B. Smitha, S. Sridhar and A. A. Khan, J. Membr. Sci., 2005, 259, 10-26.

10 M. Rikukawa and K. Sanui, Prog. Polym. Sci., 2000, 25, 14631502. 
11 L. Unnikrishnan, S. Mohanty and S. K. Nayak, High Perform. Polym., 2013, 25, 854-867.

12 X. Jin, M. T. Bishop, T. S. Ellis and F. E. Karasz, Br. Polym. J., 1985, 17, 4-10.

13 Z. Tahir, A. Ilyas, X. F. Li, M. R. Bilad, I. F. J. Vankelecom and A. L. Khan, J. Appl. Polym. Sci., 2018, 135(10), 45952.

14 H. Asghar, A. Ilyas, Z. Tahir, X. F. Li and A. L. Khan, Sep. Purif. Technol., 2018, 203, 233-241.

15 T. Y. Inan, H. Doğan, E. E. Unveren and E. Eker, Int. J. Hydrogen Energy, 2010, 35, 12038-12053.

16 F. Wang, M. Hickner, Y. S. Kim, T. A. Zawodzinski and J. E. McGrath, J. Membr. Sci., 2002, 197, 231-242.

17 C. Y. Wang, Y. P. Zhou, C. Xu, X. Y. Zhao, J. Li and Q. Ren, Int. J. Hydrogen Energy, 2018, 43, 20739-20749.

18 M. K. Ahn, B. Lee, J. Jang, C. M. Min, S. B. Lee, C. Pak and J. S. Lee, J. Membr. Sci., 2018, 560, 58-66.

19 K. Kang and D. Kim, J. Membr. Sci., 2019, 578, 103-110.

20 W. Zheng and C. J. Cornelius, Polymer, 2016, 103, 104-111.

21 J. Yuk, S. Lee, A. F. Nugraha, H. Lee, S. H. Park, S. D. Yim and B. Bae, J. Membr. Sci., 2016, 518, 50-59.

22 A. V. Talyzin, T. Hausmaninger, S. J. You and T. Szabo, Nanoscale, 2014, 6, 272-281.

23 S. J. Lue, Y.-L. Pai, C.-M. Shih, M.-C. Wu and S.-M. Lai, J. Membr. Sci., 2015, 493, 212-223.

24 K. Feng, B. B. Tang and P. Y. Wu, ACS Appl. Mater. Interfaces, 2013, 5, 1481-1488.

25 C. W. Lin and Y. S. Lu, J. Power Sources, 2013, 237, 187-194. 26 Y. Heo, H. Im and J. Kim, J. Membr. Sci., 2013, 425-426, 11-22. 27 R. Kumar, M. Mamlouk and K. Scott, RSC Adv., 2014, 4, 617-623.

28 H. C. Chien, L. D. Tsai, C. P. Huang, C. Y. Kang, J. N. Lin and F. C. Chang, Int. J. Hydrogen Energy, 2013, 38, 13792-13801. 29 I. Nicotera, C. Simari, L. Coppola, P. Zygouri, D. Gournis, S. Brutti, F. D. Minuto, A. S. Arico, D. Sebastian and V. Baglio, J. Phys. Chem. C, 2014, 118, 24357-24368.

30 A. K. Sahu, K. Ketpang, S. Shanmugam, O. Kwon, S. Lee and H. Kim, J. Phys. Chem. C, 2016, 120, 15855-15866.

31 R. Kumar, M. Mamlouk and K. Scott, Int. J. Electrochem., 2011, 2011, 7.

32 Ravikumar and K. Scott, Chem. Commun., 2012, 48, 5584-5586. 33 T. Bayer, R. Selyanchyn, S. Fujikawa, K. Sasaki and S. M. Lyth, J. Membr. Sci., 2017, 541, 347-357.

34 Z. Jiang, Y. Shi, Z.-J. Jiang, X. Tian, L. Luo and W. Chen, J. Mater. Chem. A, 2014, 2, 6494-6503.

35 H. Y. Hou, X. H. Hu, X. X. Liu, W. Hu, R. J. Meng and L. Li, Ionics, 2015, 21, 1919-1923.

36 Z. Wang, J. Wang, Z. Li, P. Gong, X. Liu, L. Zhang, J. Ren, H. Wang and S. Yang, Carbon, 2012, 50, 5403-5410.

37 A. Mathkar, T. N. Narayanan, L. B. Alemany, P. Cox, P. Nguyen, G. H. Gao, P. Chang, R. Romero-Aburto, S. A. Mani and P. M. Ajayan, Part. Part. Syst. Charact., 2013, 30, 266-272.

38 K. Samanta, S. Some, Y. Kim, Y. Yoon, M. Min, S. M. Lee, Y. Park and H. Lee, Chem. Commun., 2013, 49, 8991-8993.

39 W. Feng, P. Long, Y. Y. Feng and Y. Li, Adv. Sci., 2016, 3(7), 1500413.

40 R. R. Nair, W. C. Ren, R. Jalil, I. Riaz, V. G. Kravets, L. Britnell, P. Blake, F. Schedin, A. S. Mayorov, S. J. Yuan,
M. I. Katsnelson, H. M. Cheng, W. Strupinski, L. G. Bulusheva, A. V. Okotrub, I. V. Grigorieva, A. N. Grigorenko, K. S. Novoselov and A. K. Geim, Small, 2010, 6, 2877-2884.

41 W. S. Hummers and R. E. Offeman, J. Am. Chem. Soc., 1958, 80, 1339.

42 S. Stankovich, D. A. Dikin, R. D. Piner, K. A. Kohlhaas, A. Kleinhammes, Y. Jia, Y. Wu, S. T. Nguyen and R. S. Ruoff, Carbon, 2007, 45, 1558-1565.

43 D. C. Marcano, D. V. Kosynkin, J. M. Berlin, A. Sinitskii, Z. Z. Sun, A. Slesarev, L. B. Alemany, W. Lu and J. M. Tour, ACS Nano, 2010, 4, 4806-4814.

44 Y. Si and E. T. Samulski, Nano Lett., 2008, 8, 1679-1682.

45 S. Stankovich, R. D. Piner, S. T. Nguyen and R. S. Ruoff, Carbon, 2006, 44, 3342-3347.

46 C. K. Chua and M. Pumera, J. Mater. Chem. A, 2013, 1, 18921898.

47 S. Stankovich, D. A. Dikin, O. C. Compton, G. H. B. Dommett, R. S. Ruoff and S. T. Nguyen, Chem. Mater., 2010, 22, 4153-4157.

48 S. Sun, C. Wang, M. Chen and M. Li, Chem. Phys. Lett., 2013, 561-562, 166-169.

49 O. Jankovsky, P. Simek, D. Sedmidubsky, S. Matejkova, Z. Janousek, F. Sembera, M. Pumera and Z. Sofer, RSC Adv., 2014, 4, 1378-1387.

50 B. Lian, S. De Luca, Y. You, S. Alwarappan, M. Yoshimura, V. Sahajwalla, S. C. Smith, G. Leslie and R. K. Joshi, Chem. Sci., 2018, 9, 5106-5111.

51 A. R. Thiruppathi, B. Sidhureddy, W. Keeler and A. Chen, Electrochem. Commun., 2017, 76, 42-46.

52 K. Shimizu, A. Shchukarev, P. A. Kozin and J.-F. Boily, Langmuir, 2013, 29, 2623-2630.

53 X. Yang, X. Jia and X. Ji, RSC Adv., 2015, 5, 9337-9340.

54 M. Wahlqvist and A. Shchukarev, J. Electron Spectrosc. Relat. Phenom., 2007, 156, 310-314.

55 N. B. Colthup, L. H. Daly and S. E. Wiberley, Introduction to Infrared and Raman Spectroscopy, Elsevier Science, 1990.

56 C. Hontoria-Lucas, A. J. López-Peinado, J. d. D. LópezGonzález, M. L. Rojas-Cervantes and R. M. Martín-Aranda, Carbon, 1995, 33, 1585-1592.

57 G. I. Titelman, V. Gelman, S. Bron, R. L. Khalfin, Y. Cohen and H. Bianco-Peled, Carbon, 2005, 43, 641-649.

58 Y. Wang, W. C. Lee, K. K. Manga, P. K. Ang, J. Lu, Y. P. Liu, C. T. Lim and K. P. Loh, Adv. Mater., 2012, 24, 4285-4290.

59 S. S. Kocha, J. D. L. Yang and J. S. Yi, AIChE J., 2006, 52, 19161925.

60 K. R. Cooper, In situ pem fuel cell fuel: Fuel crossover and electrical short circuit measurement, 2008.

61 T. Bayer, S. R. Bishop, M. Nishihara, K. Sasaki and S. M. Lyth, J. Power Sources, 2014, 272, 239-247.

62 W. Vielstich, H. A. Gasteiger and H. Yokokawa, Handbook of Fuel Cells: Fundamentals Technology and Applications: Advances in Electrocatalysis, Materials, Diagnostics and Durability, Wiley-Blackwell, 2009.

63 S. A. Vilekar and R. Datta, J. Power Sources, 2010, 195, 22412247. 